\title{
Caderno Seminal Digital \\ MEDIA EFFECTS: EFEITOS CUMULATIVOS E DE LONGO PRAZO DOS MODELOS TEÓRICOS
}

Paula Karini Dias Ferreira Amorim*

Resumo: Este trabalho tem por finalidade contextualizar os estudos dos efeitos da comunicação de massa desde a perspectiva dos efeitos limitados até os efeitos a longo prazo acerca da influência da opinião pública. Apresenta-se uma breve contextualização dos principais modelos teóricometodológicos - agenda-setting, cultivo, efeito de terceira pessoa, priming, framing - que procuram explicar a influência dos meios de comunicação de massa a longo prazo e suas consequências. Os modelos teóricos atuais que procuram compreender os fenômenos decorrentes dos efeitos dos meios de comunicação de massa sobre a opinião pública, ao mesmo tempo, ampliam e sedimentam os métodos de investigação e o escopo do entendimento desses efeitos na construção da realidade.

Palavras-chave: Media Effects; Estudos dos Efeitos; Agendasetting, Cultivo, Efeito de terceira pessoa, Priming, Framing.

Abstract: This paper aims to contextualize the study of the effects of mass communication from the perspective of the

* Paula Karini Dias Ferreira Amorim é Doutora em Comunicação e Culturas Contemporâneas pela FACOM/Universidade Federal da Bahia. Docente do Instituto Federal de Educação, Ciência e Tecnologia do Tocantins.

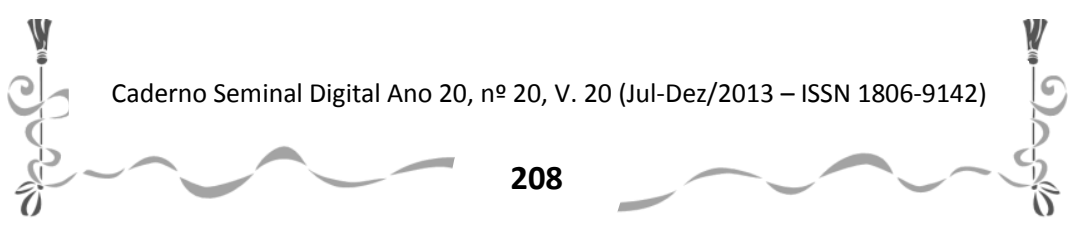


limited effects to the long-term effects on the influence of public opinion. It presents a brief contextualization of the main theoretical and methodological models - agenda-setting, cultivation, third-person effect, priming, framing - that seek to explain the influence of mass communication and long-term consequences. The current theoretical models seek to understand the phenomena resulting from the effects of mass communication on public opinion, at the same time, extend and collect the research methods and the understanding scope of these effects in the construction of reality.

Keywords: Media Effects; Studies of effects; Agenda-setting, Cultivation, Third-person effect, Priming, Framing.

\section{INTRODUÇÃO}

Muitos estudiosos da comunicação têm se dedicado à compreensão dos efeitos e das influências da comunicação de massa sobre suas audiências. Como resultado desse esforço tem-se uma série de formulações que procuram descrever e explicar como ocorre e no que resulta a exposição a formas específicas de conteúdo de mensagem por meio de determinado veículo de comunicação de massa. Os postulados já consagrados são fruto da realidade e do contexto de sua época e, pela evolução das investigações sobre os fenômenos decorrentes dos efeitos da comunicação de massa, mais a própria dinâmica sócio-política-tecnológica novas indagações são postas para o campo da comunicação de massa.

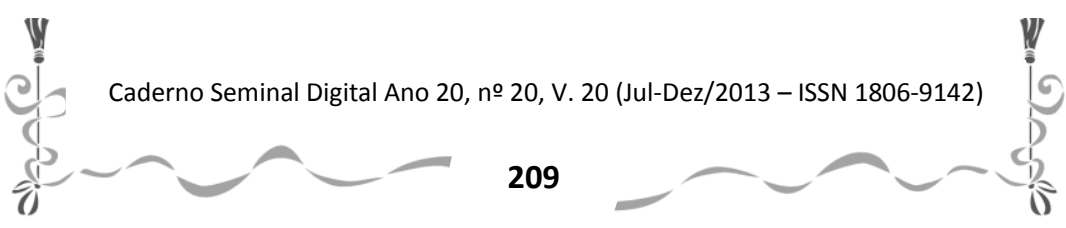


Para que se alcance o entendimento preliminar, pelo menos, do que tem sido considerado a "ponta da lança" em termos de investigação dos media effects pretende-se desenvolver neste artigo uma breve contextualização dos estudos dos efeitos da comunicação de massa desde a perspectiva dos efeitos limitados até os efeitos a longo prazo acerca da influência da opinião pública. Pretende-se também apresentar uma breve contextualização dos principais modelos teórico-metodológicos - agenda-setting, cultivo, efeito de terceira pessoa, priming e framing.

\section{DOS EFEITOS LIMITADOS AOS EFEITOS A LONGO PRAZO}

Os estudos acumulados sobre a comunicação de massa são fruto de determinações que transcendem a mera evolução cronológica. Nota-se que as teorias que procuram dar conta do fenômeno da comunicação de massa surgem envoltas e imersas ao contexto social, histórico e econômico vigentes em sua época e têm uma profunda relação com as teorias sociológicas. Assim, cada modelo teórico-metodológico busca compreender e explicar os efeitos decorrentes da exposição aos veículos de comunicação de massa à luz da realidade da sociedade. Ressalte-se que a sociedade evolui através de um processo dinâmico e complexo e, que em função disso as premissas de cada modelo ganham contornos delimitados por paradigmas psicológicos, sociológicos e antropológicos.

Os primeiros estudos defendiam que os meios de comunicação de massa tinham poder de persuadir por meio

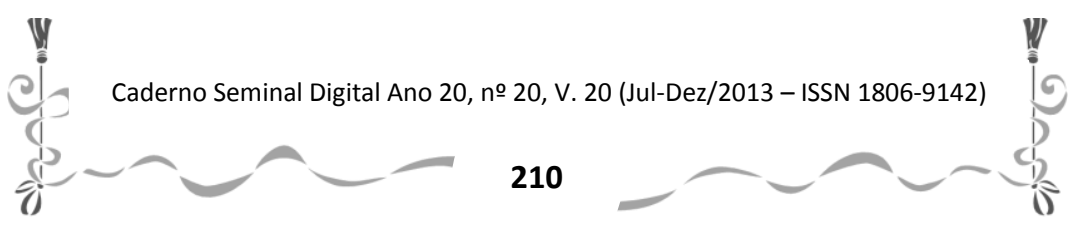


de mensagens (estímulo) recebidas pela audiência de modo uniforme e que gerariam respostas imediatas e diretas. Cite-se como exemplo os experimentos realizados com as propagandas veiculadas durante a Primeira Guerra Mundial e as que levavam as pessoas a consumirem massivamente produtos em quantidade e variedade nunca antes imaginada para época (DEFLEUR; BALL-ROKEACH, 1993). Novos estudos realizados na década de 30 conduziram a conclusões significativas sobre a influência que os atributos pessoais e sociais exerciam sobre a percepção da mensagem, o que resultou em explicações do fenômeno por meio da influência seletiva. Segundo essa abordagem nem todas as pessoas recebiam a mensagem uniformemente. Variados fatores definiriam essa influência, sejam as diferenças individuais, as diferenças sociais ou os relacionamentos sociais das pessoas atingidas pelo conteúdo da mensagem.

A teoria dos efeitos limitados desloca, portanto, o acento de um nexo causal direto entre propaganda de massa e manipulação da audiência para um processo mediato de influência, em que as dinâmicas sociais cruzam com os processos de comunicação. (WOLF, 2005, p.37)

Assim, nesse contexto, os efeitos dos meios de comunicação ocorrem devido às forças sociais que caracterizam um determinado período e uma determinada

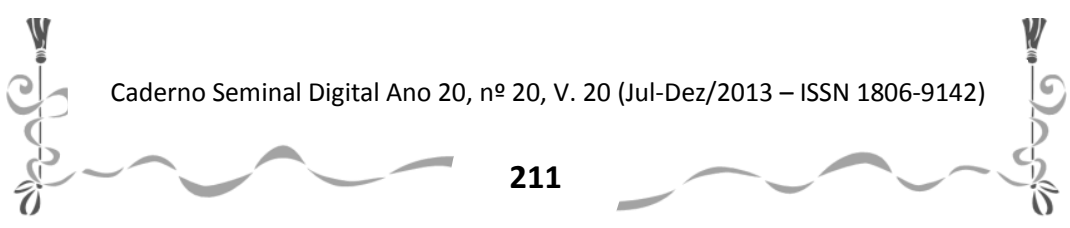


Caderno Seminal Digital

î.

sociedade (WOLF, 2005). O foco de análise se concentrou no entendimento de como se dava a relação entre o conteúdo da mídia e as respostas dadas pelas pessoas no aqui e no agora. A compreensão de como o indivíduo assiste, interpreta, recorda e age conforme as mensagens que recebe são, resumidamente, o alvo da teoria da influência seletiva cuja proposta básica sustentou-se em quatro pilares de acordo com DeFleur; Ball-Rokeach (1993):

I) As variações cognitivas das pessoas são resultado das suas experiências de aprendizagem e interação nos ambientes social e cultural.

II) As sociedades complexas por meio de cada uma das suas categorias sociais provêem subculturas que possibilitam aos seus membros criarem e compartilharem crenças, atitudes e modelos de ação que atendam aos seus interesses e ajudem a enfrentar desafios.

III) Os vínculos sociais da sociedade urbanoindustrial no que se refere a família, amigos, vizinhos e colegas de trabalho são mais expressivos.

IV) A existência de diferenças individuais em estruturas cognitivas, de subculturas de categorias sociais e de vínculos sociais entre os

Caderno Seminal Digital Ano 20, no 20, V. 20 (Jul-Dez/2013 - ISSN 1806-9142)
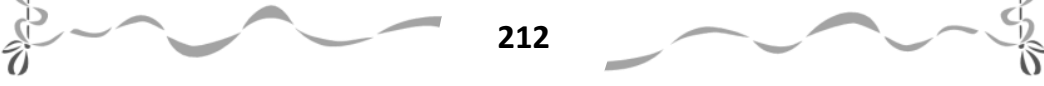
membros da audiência leva, portanto, a padrões seletivos de atenção, percepção, recordação e ação em relação a formas específicas de conteúdo.

A teoria da influência seletiva concentrou-se no exame do que ocorre com os indivíduos de maneira imediata, ou seja, logo após a exposição à mensagem persuasiva. Contudo, DeFleur; Ball-Rokeach (1993) asseveram a necessidade de desenvolver processos aperfeiçoados para identificar, avaliar e interpretar as consequências a longo prazo, sutis e indiretas da participação de diferentes sistemas de comunicação. A transição dos efeitos limitados para os efeitos com consequências de longo período foi fruto da consciência de que as comunicações não intervêm diretamente no comportamento explícito somente, mas têm a tendência de influenciar o modo como o destinatário organiza a própria imagem do ambiente. (Roberts. In: WOLF, 2005, p.138)

Do ponto de vista da pesquisa científica o novo paradigma traz algumas diferenças na visão de Noelle Neumann citado por Wolf (2005). No quadro a seguir apresentam-se as principais diferenças entre os paradigmas dos efeitos limitados e dos efeitos a longo prazo.

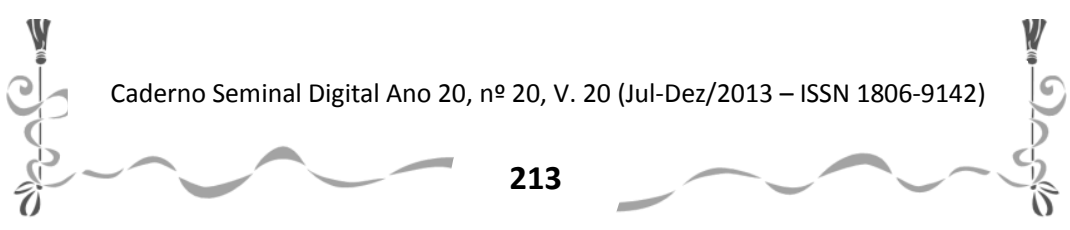


Caderno Seminal Digital

Velho paradigma

Novo paradigma

Estudos de casos individuais.

Cobertura global do sistema da mídia com foco em determinadas áreas temáticas.

Levantamentos de dados a Uso de métodos complexos partir de entrevistas com o e integrados. público.

Observações e medições das mudanças de postura e opinião.
Reconstrução do processo pelo qual o indivíduo modifica a própria representação da realidade social.

Quadro 1: Diferenças de pesquisa entre o velho e o novo paradigma Fonte: Wolf (2005)

O foco de estudo dos problemas dos efeitos muda. 0 tipo de efeito não se refere mais às atitudes, aos valores, aos comportamentos do receptor, mas ao efeito cognitivo em relação aos sistemas de conhecimentos que são assumidos e estruturados com estabilidade em função do consumo de comunicações de massa. Outra mudança diz respeito ao quadro temporal. Enquanto os estudos se detinham aos efeitos pontuais da exposição à mensagem, a nova

Caderno Seminal Digital Ano 20, no 20, V. 20 (Jul-Dez/2013 - ISSN 1806-9142)

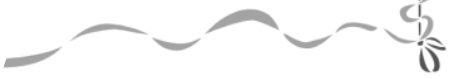


Caderno Seminal Digital

î.

perspectiva procura entender os efeitos gerados cumulativamente e sedimentos ao longo do tempo. Outra mudança a ser destacada é a passagem do modelo transmissivo de comunicação para o modelo centrado no processo de significação. A mídia, portanto, contribuirá na construção da realidade e por isso influenciará na estruturação da imagem da realidade social por um longo período, bem como na organização de novos elementos de imagem e na formação de opiniões e crenças (Roberts citado por Wolf, 2005). A articulação conjunta da ação dos meios de comunicação de massa e o conjunto de conhecimentos sobre a realidade social, (re)forma a cultura sobre a qual atuam dinamicamente. Em função dessa articulação Wolf (2005) destaca três características da mídia: a acumulação, a consonância e a onipresença. A acumulação diz respeito à capacidade que a mídia tem de manter um determinado tema em destaque mesmo depois de algum tempo pela maneira de funcionamento da cobertura informativa do sistema de comunicação de massa. Já a consonância refere-se à existência de traços comuns e semelhantes entre os veículos, o que torna as mensagens, em sua substância, mais parecidas. $E$, por fim, a onipresença refere-se a difusão quantitativa dos meios de comunicação de massa e ao fato de que saber público tem qualidade particular, pois sabe-se publicamente que este saber é publicamente conhecido.

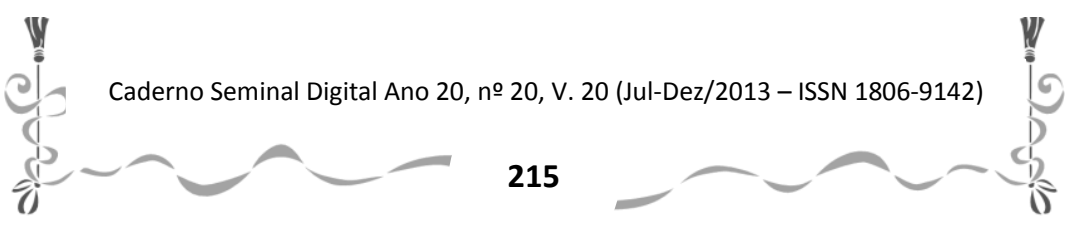


Por meio das características anteriormente citadas nota-se que há a disponibilidade para a expressão e para a visibilidade dos pontos de vistas disseminados pela mídia, o que leva a uma adequação dessa visibilidade com os que ainda não têm uma posição própria. Isso pode resultar na regulação e adaptação da opinião pública como reflexo do que é difundido pela mídia. Portanto, o estudo dos efeitos a longo prazo inaugura, conforme Fishman citado por Wolf (2005), a compreensão dos media effects por meio dos processos e dos modos com os quais os meios de comunicação de massa criam condições da nossa experiência do mundo para além das esferas de interações que temos cotidianamente. Na seção a seguir apresentam-se alguns dos principais e mais recentes modelos teórico-metodológicos que propõem analisar, descrever e explicar a influência dos meios de comunicação de massa.

\section{MODELOS TEÓRICO-METOdOLÓGICOS DE EFEITOS A LONGO}

Depois de tratado da transição de foco dos efeitos limitados para os efeitos a longo prazo, discutiremos nessa seção modelos teóricos mais desenvolvidos e fundamentados na concepção de que a comunicação de massa exercerá influência comportamental e cognitiva na sua audiência direta e indireta. Entre os modelos teóricos de abordam desse processo encontram-se os estudos que envolvem os conceitos de agenda-setting, cultivo, efeito de terceira pessoa, framing

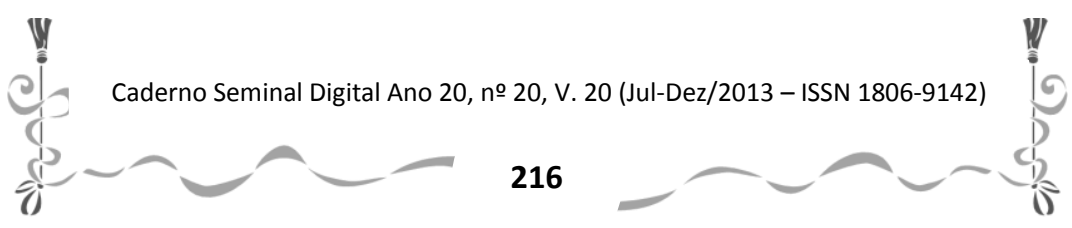


Caderno Seminal Digital

e priming. Mesmo existindo controvérsias a respeito do uso desses modelos teóricos e que estes sejam passíveis de discussão, as pesquisas apoiadas nas nessas hipóteses têm contribuído para a compreensão das relações entre mídia e opinião pública.

\section{1- AGENDA-SETTING}

A hipótese da agenda-setting é um dos modelos teórico-metodológicos que procura entender os efeitos da mídia a longo prazo. Walter Lippman em 1922 foi um dos pioneiros desse estudo, por meio da argumentação de que os mass media são a ligação entre eventos do mundo e as representações destes eventos em nossas mentes ${ }^{* *}$ (HARRIS et al, 2001). A sustentação fundamental dessa hipótese é a de que por consequência da atuação dos meios de comunicação de massa (televisão, jornais, rádio etc.) o público toma ciência ou ignora, dá atenção ou descuida, dá ênfase ou negligência questões específicas dos cenários públicos. Há, segundo essa hipótese, uma tendência de as pessoas incluírem ou excluírem dos próprios conhecimentos aquilo que os meios de comunicação incluem ou excluem do seu conteúdo McCombs e Shaw (1972). Desta forma, o foco fundamental do agendasetting é como as pessoas compreendem a realidade social modificada pelos meios de comunicação de massa. Pois, se os meios de comunicação não conseguem influenciar fortemente

** As traduções deste artigo são de responsabilidade da autora.

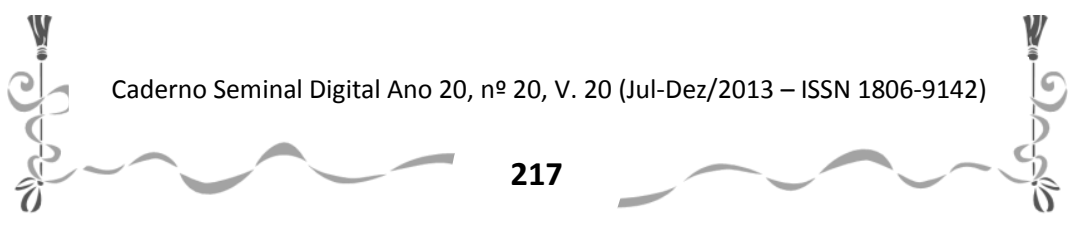


Caderno Seminal Digital

î

a sua audiência no que pensar, pode, pois, influenciá-la sobre quais temas pensar.

As pesquisas desenvolvidas sobre essa hipótese têm demonstrado que existe diferença entre a eficácia da agendasetting entre os meios televisivos e a impressa. A explicação para isso é que enquanto a informação televisiva tende a planificar a relevância do que é transmitido, os meios impressos fornecem aos seus leitores informação mais aprofundada, constante e visível (WOLF, 2005). Outro aspecto relevante das pesquisas sobre a teoria do agendamento é em relação aos temas eleitorais. Os resultados de um estudo realizado durante as eleições regionais e municipais da Espanha no ano de 1995 por McCombs et al (1997) demonstraram a influência da cobertura das notícias sobre a relevância de questões e outros assuntos na agenda pública. Esse fenômeno foi denominado pelos autores de agendasetting de primeiro nível. Contudo, nesta mesma pesquisa foi incluída a possibilidade de transferência da relevância dos atributos e dos frames da agenda da mídia para a agenda pública, culminando na elaboração da agenda-setting de segundo nível. Segundo a qual estabelece que os news media não somente dizem o que pensar, mas também como pensar sobre algo. Kiousis e outros (1999) também investigaram sobre a agenda de segundo nível. O enfoque do estudo foi nos atributos da imagem de um determinado candidato. Segundo os mesmos autores o conceito de framing está

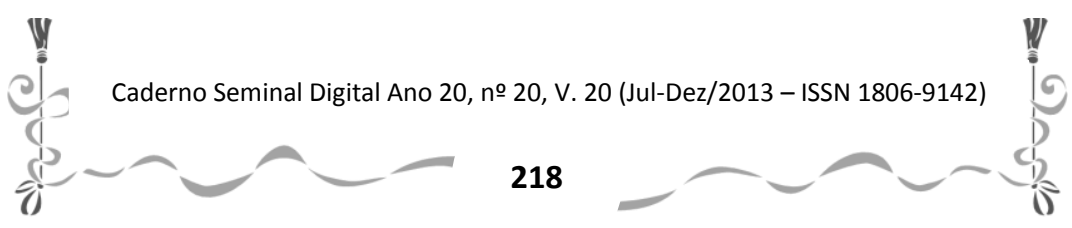


Caderno Seminal Digital

Aิ

intrinsecamente ligado a agenda-setting de atributos, pois aquele desenha a atenção para certos atributos e distância a atenção para outros. A hipótese do framing será abordada em seção própria neste texto.

\section{2- CULTIVO}

A hipótese do cultivo mediático, também denominada como teoria do cultivo ou teoria do efeito cultivado procura demonstrar que uma sociedade que tem a televisão como principal fonte de conhecimento, tende a perceber o mundo em que vive conforme o que é proposto pelo texto mestre desse aparato tecnológico. O precursor dessa premissa foi George Gerbner em 1969. Sua pesquisa se concentrou no entendimento das consequências para o desenvolvimento de indivíduos imersos em um ambiente cultural tipicamente centrado na TV e foi realizada por meio da análise das notícias e dos conteúdos exibidos pela televisão.

Embora pareça ter relação somente com os cuidados com plantações, o termo cultivo é empregado no mesmo sentido, só que o cultivo se dá em relação à cultura mediática, ou processo de enculturação. Neste caso o meio que possibilita esse processo é a televisão que representa fortemente a visão predominante do mundo e, nessa perspectiva, exerce em longo prazo um efeito sobre as representações e, consequentemente influencia o comportamento daqueles que a consomem.

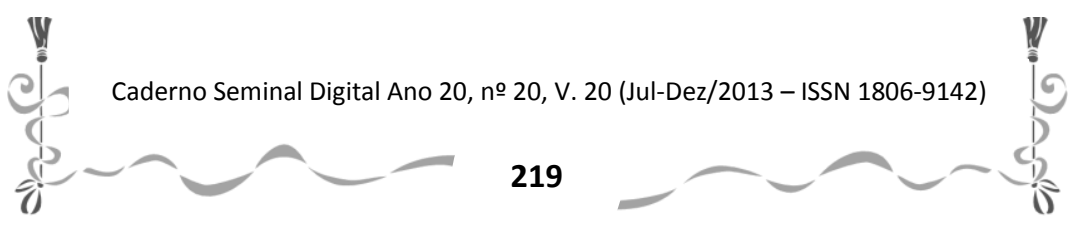


De acordo com Filho (2007) a pesquisa sobre essa hipótese foi inicialmente formulada para a compreensão de como a exposição aos conteúdos televisivos, sobretudo a violência, influenciava a opinião das pessoas sobre a possibilidade de serem vítimas de crime. Contudo, a pesquisa se alargou para a compreensão do fenômeno em relação a outras questões, como expectativa sobre o casamento, políticas públicas e realidade social.

Antes de apresentar alguns exemplos de pesquisas realizadas, faz-se necessário acrescentar a este breve contexto da hipótese do cultivo a perspectiva de análise desenvolvida por Shrum (2001), a qual trata da hipótese em dois níveis: o primeiro como os efeitos mensurados da relação entre a exposição assídua à TV e a expectativa ou probabilidade dos eventos exibidos na TV ocorrerem na realidade social; e os efeitos de segundo nível decorrentes da relação entre a exposição à televisão e os juízos de valor, atitudes e comportamentos do espectador em relação ao mundo.

Nabi e Sullivan (2001) investigaram os efeitos da hipótese do cultivo com a intenção de explorar os efeitos de segunda ordem a respeito do envolvimento dos cidadãos em medidas preventivas contra $o$ crime e também sobre possibilidades metodológicas para o aperfeiçoamento da hipótese. $O$ estudo resultou em desdobramentos que destacam a idéia da teoria da ação razoável cuja apropriação se dá para complementar a análise dos efeitos cultivados.

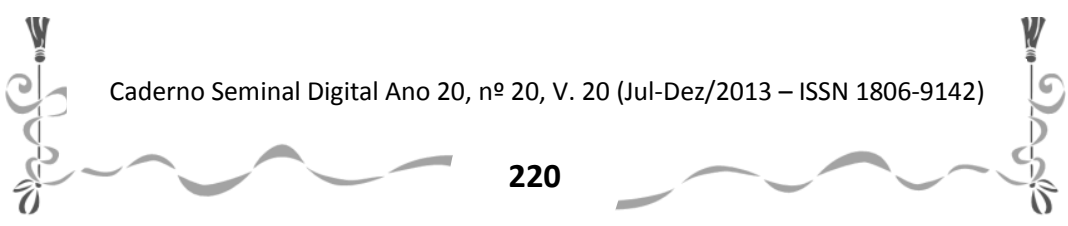


Caderno Seminal Digital

Segundo os autores "pesquisas na área têm demonstrado evidências que, sob circunstâncias apropriadas, 'visões de mundo' podem de forma confiável prognosticar intenções de comportamentos e, de fato, transformar comportamentos" (NABI; SULLIVAN, 2001, p.807).

Outro estudo a ser apresentado aqui foi o realizado por Chris Segrin e Robin Nabi (2002), neste caso uma conclusão prematura levou as autoras a afirmarem que as expectativas idealizadas pelos adolescentes em relação ao casamento e as intenções de casar foram cultivadas pelos programas de televisão que abordavam histórias de casais que tinham uma relação bem-sucedida. Essa análise negligenciou a influência de outras narrativas que abordam igualmente a relação romantizada entre homens e mulheres. Assim, alerta Filho "é imprescindível para se compreender quais efeitos são cultivados especificamente pelos media, através de suas características e gramáticas próprias, e quais são cultivados por outros atores da sociedade" (FILHO, 2007, p.13).

\section{3-EFEITO DE TERCEIRA PESSOA}

A formulação da hipótese do efeito de terceira pessoa elaborada inicialmente por Davison em 1983 "prevê que as pessoas tendem a superestimar a influência dos meios de comunicação de massa sobre as atitudes e o comportamento dos outros" (Davison, 1983, p.3). Em outras palavras, os outros indivíduos (terceira pessoa) expostos a mensagens persuasivas serão mais impactados pelo conteúdo da

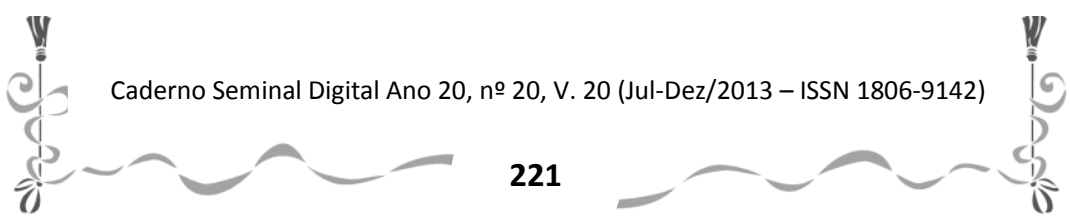


Caderno Seminal Digital

Â

mensagem do que "eu" (primeira pessoa), e isso induzirá "eles" a tomarem certas atitudes e a adotarem certos comportamentos. Desta forma, quaisquer que sejam os efeitos que as mensagens persuasivas tenham nas atitudes e no comportamento, não são em função do impacto persuasivo direto das mensagens em si. Pelo contrário, Davison (1983), afirma que os efeitos se devem às ações daqueles que antecipam alguma reação pela parte dos outros (as terceiras pessoas), e agem diferentemente como resultado disso.

Os estudos que buscam comprovar a existência desse fenômeno se concentram nos mais variados temas: eleições, consumo/moda, grupos minoritários, conflitos de guerra, assuntos polêmicos como eutanásia, campanhas antitabagismo, alimentos geneticamente modificados, automedicação, censura de conteúdos indesejados e outros. No quadro a seguir são apresentados os estudos e as descobertas sobre a hipótese do efeito da terceira pessoa.

Caderno Seminal Digital Ano 20, no 20, V. 20 (Jul-Dez/2013 - ISSN 1806-9142)
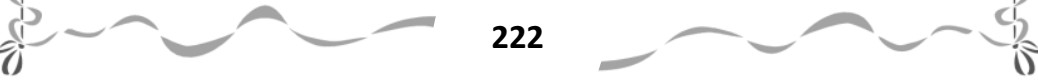
Caderno Seminal Digital

\section{As descobertas}

Estudo

Tópico da mensagem

\section{comprovam a}

hipótese do efeito

da terceira pessoa?
Cohen e

Davis

(1991)
Propaganda política negativa
Sim, para os partidários

do candidato atacado quando julgam os efeitos nos outros. Efeito da terceira pessoa reverso entre os oponentes do candidato atacado quando julgam os efeitos nos partidários do candidato.
Cohen et

al., 1988

Glynn e Ostman (1988)

Grisworld (1992)
Notícias

difamatórias

Influência percebida da opinião pública

Mensagens sobre a economia durante a campanha para as eleições
Sim

Não

\section{Sim, para opiniões de Bush, mas não para as crenças acerca dos candidatos republicanos}

Caderno Seminal Digital Ano 20, no 20, V. 20 (Jul-Dez/2013 - ISSN 1806-9142) 


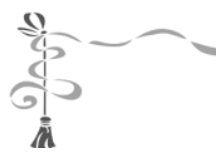

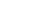

presidenciais em

Caderno Seminal Digital

1992

Gunther

(1991 a)

Gunther

(1991 b)

Gunther e

Mundy

(1993)

Gunther e

Thorson

(1992)

Lasorsa

(1989)
Notícias
difamatórias

Pornografia

Mensagens que variaram na probabilidade de benefício pessoal

Propagandas neutras e emotivas/sensaciona listas e anúncios de serviço público

ABC América e democratas.

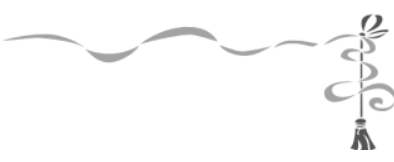

少

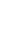

Sim, para mensagens

julgadas 'não

inteligentes para eu ser influenciado por elas' ou 'não tão boas para mim'.

Sim, para propagandas neutras. Efeito da terceira pessoa reverso para as propagandas emotivas. Nenhum efeito para os anúncios de serviço público.

Sim, e particularmente para indivíduos que se perceberam como politicamente elegíveis.

Caderno Seminal Digital Ano 20, no 20, V. 20 (Jul-Dez/2013 - ISSN 1806-9142) 


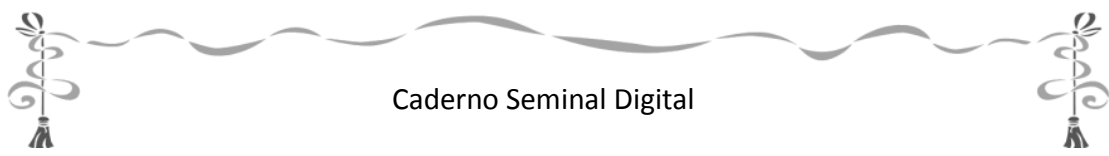

Mason

(1990)

Descrições ambíguas

de eventos

Sim

hipotéticos

Mutz

Noticias sobre

(1989)

questões

controversas de

política

Sim, e um efeito mais forte naqueles que perceberam a questão como pessoalmente importante.

Perloff et

al. (1992)

ABC América

Sim

Rucinski e Propaganda política, Salmon telejornais, debates

Sim

(1990)

e prévias de votação.

Efeitos da mídia na

Tiedge at vida pessoal

al. (1991)

(relatório de

$\operatorname{Sim}$

medidas a cerca de

si mesmo)

Quadro 2 - Pesquisa sobre a Hipótese do Efeito da Terceira Pessoa Fonte:

Perloff (1993)

Caderno Seminal Digital Ano 20, no 20, V. 20 (Jul-Dez/2013 - ISSN 1806-9142) 
Caderno Seminal Digital

Contudo, segundo Perloff (1993), o efeito da terceira pessoa não emerge em todas as circunstâncias e nem para todas as pessoas, conforme quadro anteriormente apresentado. $O$ efeito tende a se manifestar quando o indivíduo entende que o conteúdo das mensagens não é benéfico, ou seja, aborda questões negativas ou insatisfatórias. O contrário também acontece, quando o conteúdo da mensagem é positivo, o efeito de terceira pessoa tende a ser menor. Outro fator importante que fora pesquisado e encontrado por Gunther (1991) refere-se à confiabilidade da fonte da notícia, quanto mais confiável menor a tendência do efeito se manifestar. Outra condição apontada por Perloff que o efeito de terceira pessoa ocorreu foi em relação à demografia e outros assuntos relacionados.

É importante apontar que variáveis demográficas como idade e nível de escolaridade refletem ou apontam indiretamente fatores conceituais subjacentes que de fato causam impacto na percepção dos efeitos da mídia mais nos outros que em si mesmo. Nível de escolaridade pode ser indicativo de habilidade (qualificação) percebida, as quais (como Lasorsa, 1989 encontrou) aumentam a força do efeito da terceira pessoa. A idade pode refletir acessibilidade das atitudes sociais e confiança

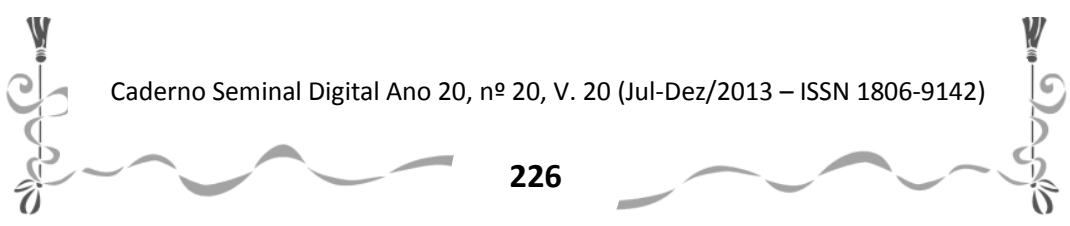


Caderno Seminal Digital

na habilidade de alguém a resistir às tentativas de influência. (PERLOFF, 1993, p.175)

Por fim, outro elemento identificado por Perloff (1993) como tendencioso para ocorrer o efeito de terceira pessoa diz respeito à distância social. Contudo, o mesmo autor adverte que esta é uma variável complexa que inclui vários componentes, como a similaridade percebida, familiaridade e identificação.

Em função do entendimento que o conteúdo da mídia pode resultar em efeitos negativos, do esse mesmo raciocínio, Chia e outros (2004) sinalizam que parte do pressuposto de terceira pessoa levanta duas possibilidades, uma preventiva e outra punitiva. A preventiva concentra-se na censura como ação preventiva para proteger os outros da influência adversa da mídia. Já a punitiva reflete a intenção de penalizar a mídia pelo dano causado ao sujeito pela comunicação negativa ou indesejada. A censura representa uma tentativa de impedir a circulação desses conteúdos entendidos como impróprios.

\section{3- FRAMING}

O framing foi um termo usado por Erving Goffman em 1974 para "caracterizar como os indivíduos compreendem e respondem às situações sociais a partir do modo como organizam a vida cotidiana" Gutmann (2006, p.32). Esse processo resulta em esquemas interpretativos que conduzem o público na localização, na percepção, na identificação e na

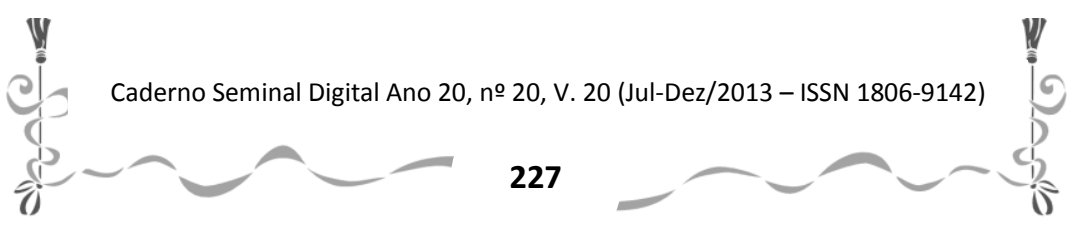


Caderno Seminal Digital

î

rotulação de informações e eventos. Framing refere-se a uma "moldura" que é delineada para questões ou acontecimentos cobertos pela mídia, por meio da qual o público interpreta esses mesmos acontecimentos. Para Entman, citado por Gutmann (2006):

enquadrar é selecionar alguns aspectos de uma realidade percebida e fazer eles mais salientes no texto comunicativo de modo a promover uma definição particular de um problema, interpretação causal, avaliação moral e/ou um tratamento recomendado para o item descrito. (Entman. In: Guttmann, 1993: 52)

Há na literatura discussões em torno da conceituação e da pertinência do framing como aplicável ao estudo de questões relacionadas à área. Entman, citado por Scheufele (1999), refere-se ao framing como um conceito disperso que carece de mais clareza. Iyengar; Kinder, citados por Scheufele (1999), têm estudado o framing em combinação com outros conceitos como a agenda-setting e o priming. Já McCombs; Shaw; Weaver, citados por Scheufele (1999), têm trabalhado em seus estudos o framing como uma extensão da agendasetting, o que denominam de agenda-setting de segundo nível.

Nota-se que a maioria das pesquisas realizadas para compreender o framing pressupõe que os media frames têm um impacto significante no modo como as pessoas percebem,

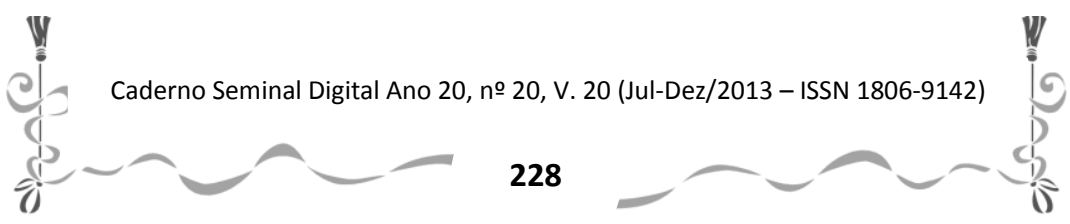


Caderno Seminal Digital

id

entendem e debatem questões públicas. Dietram Scheufele (1999) analisou o framing como uma teoria dos media effects visando formular um modelo de como se processa o framing. Para alcançar seu objetivo ele relacionou os processos de agendamento e de enquadramento de notícias, e seus possíveis efeitos no público. Baseou-se também em uma tipologia de suas diversas aplicações. Concluiu que as pesquisas na área, sejam elas voltadas para os quadros de referência da audiência ou da mídia, devem levar em conta quatro relações-chave: a construção do enquadramento (framing building); o processo de enquadramento (framing setting); os seus efeitos nos indivíduos (individual-level effects of framing) e a relação entre os framings utilizados pela audiência e aqueles construídos pela mídia. A figura a seguir ilustra o modelo de processamento do framing desenvolvido por Scheufele (1991).

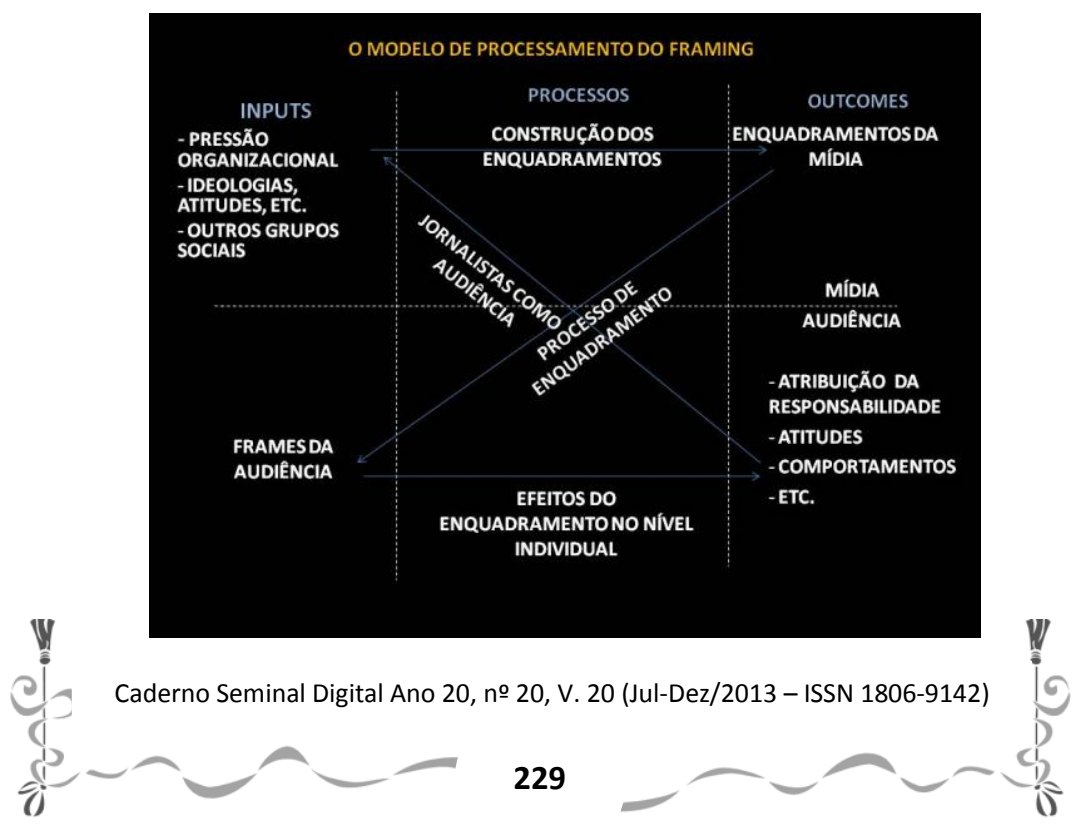


Caderno Seminal Digital

Figura 1: Modelo de processamento do framing

Fonte: Scheufele (1999)

Entman, citado por Gutmann (2006), identificou cinco elementos para localizar o enquadramento da reportagem. São eles: as palavras-chave, as metáforas, os conceitos, os símbolos e as imagens enfatizadas na narrativa jornalística. Assim, segundo Gutmann (2006) o framing pode ser reconhecido por meio da observação de imagens visuais e palavras repetidas muitas vezes em um mesmo texto midiático para tornar algumas idéias mais aparentes que outras.

Outra pesquisa sobre o framing foi realizada por Shen (2004) que demonstrou que os efeitos dos enquadramentos usados nas propagandas políticas podem ser analisados à luz de dois tipos de frames: os que focam os temas e as propostas dos candidatos e os que molduram seus atributos pessoais e relacionou esses tipos de frames às perspectivas que exercem efeitos nas respostas cognitivas dos eleitores em relação às suas avaliações políticas. Outra defesa do autor diz respeito ao nível de moderação do enquadramento devido a bagagem cultural e ao nível de conhecimento prévio dos, por exemplo, eleitores sobre os temas políticos, pressupondo que esses aspectos poderão incrementar ou enfraquecer os efeitos do framing (Gutmann, 2004).

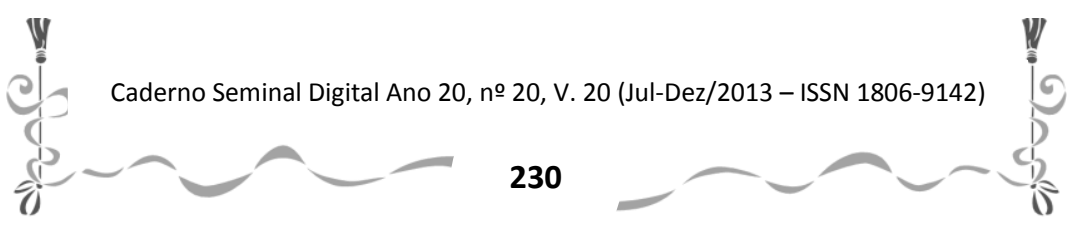


Caderno Seminal Digital

A

2.4-PRIMING

O último, mas não menos importante modelo teórico a ser discutido é a hipótese do priming. Processo pelo qual são acionadas construções mentais que podem influenciar como os indivíduos avaliam outros conceitos e idéias. Segundo Sheafer; Weiman (2005) o priming pode ser considerado como uma extensão da agenda-setting. Os autores argumentam que certas questões ganham mais destaque que outras nos meios de comunicação e essa ação conduz à hierarquização dos temas, o que faz com que o público busque na sua memória e reconheça a mensagem como importante. Esse efeito tem sido empregado para analisar a performance de políticos, a eficácia de propagandas e anúncios, temas polêmicos etc.

\section{CONSIDERAÇÕES FINAIS}

As possibilidades apresentadas neste artigo são guiadas pela busca da superação do paradigma velho - efeitos limitados - para o paradigma novo - efeitos cumulativos, assim como pela necessidade de compreender os efeitos a longo prazo dos media effects e suas relações com os temas e ângulos de abordagem pautados pela mídia. $O$ entendimento acumulado até aqui aponta para a necessidade de considerar que os modelos teóricos apresentados têm um caráter complementar. Principalmente entre os modelos do cultivo, agenda-setting e framing. Pretendeu-se com este artigo, observar certas apropriações dos principais modelos teóricometodológicos e ressaltar suas características e o foco de

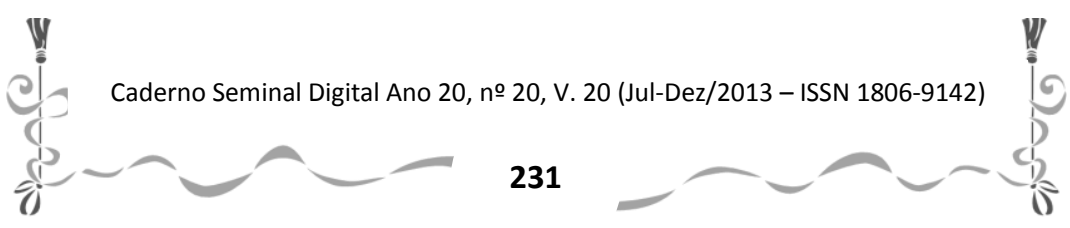


Caderno Seminal Digital

pesquisa de cada. Cabe destacar também a fragilidade metodológica das propostas de mensuração dos efeitos constatados.

Vê-se que está cada vez mais claro que o tipo de efeito que interessa às atuais pesquisas já não corresponde simplesmente a mudanças de atitudes e comportamentos, mas atua sobre os sistemas de conhecimento que o indivíduo assume e estrutura sobre o seu consumo midiático. O esquema a seguir procura demonstrar os modelos teóricos descritos neste texto.

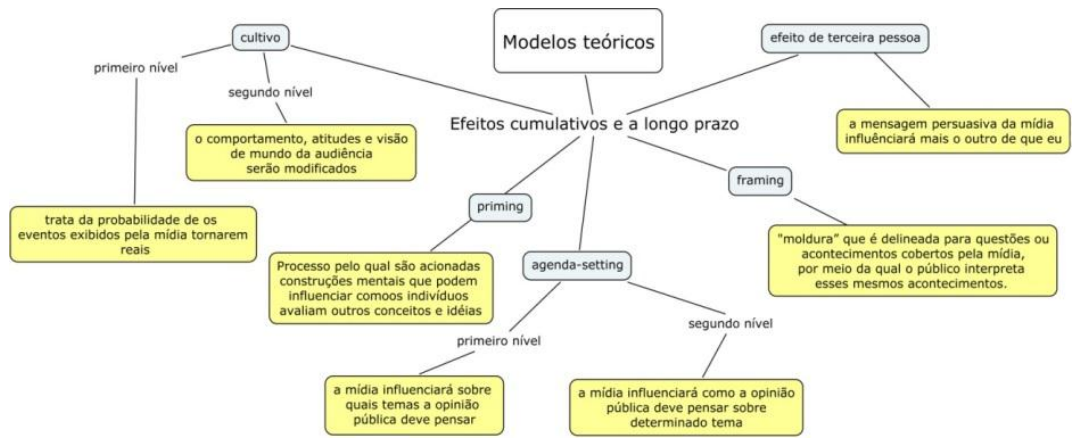

Por fim, cabe destaque aos aspectos que referem-se ao nível de complementaridade entre os modelos e a busca pela compreensão dos efeitos da mídia à luz dos dispositivos de análise mais apropriados.

\section{REFERÊNCIAS BIBLIOGRÁFICAS:}

CHIA Stella C.; LU Kerr-Hsin; MCLEOD, Douglas M. Sex, Lies, and Video Compact Disc: A Case Study on Third-Person Perception and

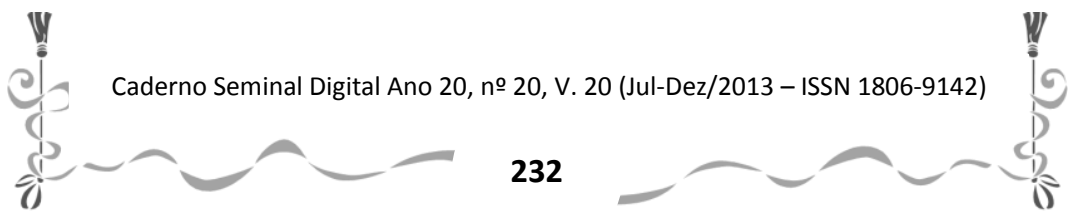


Caderno Seminal Digital

Motivations for Media Censorship. In: Communication Research, vol.31, n.1, february 01, 2004, pp.109-130.

DAVISON, W. Phillips. The third-person effect in communication. In: Public Opinion Quarterly, vol.47, 1983, pp.1-15.

DEFLEUR, M.; BALL-ROKEACH, S. Teorias da comunicação de massa. 5ed. Rio de Janeiro: Jorge Zahar, 1993.

FILHO, Jorge Luiz Cunha Cardoso. Cultivo mediático e suas consequências: um problema e duas propostas para análise de efeitos dos media. IN: Revista Contemporânea, vol.5, n.1 e 2, dezembro, 2007.

GUNTHER, A. What We Think Others Think: Cause and Consequence in the Third-Person Effect. IN: Communication Research, vol.18, n.3, june, 1991, pp.355-372.

GUTMANN, Juliana Freire. Quadros narrativos pautados pela mídia: framing como segundo nível do agenda-setting? In: Revista Contemporânea, vol.4, n 1, junho-2006, pp.25-50.

HARRIS, Phil; KOLOVOS, Ioannis; LOCK, Andrew. Who sets the agenda? $\mathrm{Na}$ analysis of agenda setting and press coverage in the 1999 Greek European elections. In: European Journal of Marketing, vol.35, n.9-10, 2001, pp.1117-1135.

KIOUSIS, Spiro; BANTIMAROUDIS, Philemon; BAN, Hyun. Candidate Image Attributes: experiments on the substantive dimension of level agenda setting. In: Communication Research, vol.26, n.4, August, 1999, pp.414-428.

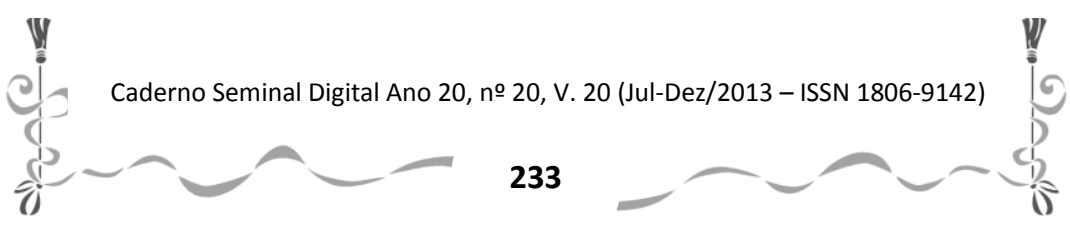


Caderno Seminal Digital

MCCOMBS, Maxwell E.; SHAW, Donald L. The agenda-setting function of mass media. In: The Public Opinion Quarterly, vol.36, n. , Summer, 1972, pp.176-187.

MCCOMBS, Maxwell; LLAMAS, Juan Pablo; LOPEZ-ESCOBAR, Esteban; REY, Federico. Candidate images in Spanish elections: second-level agenda-setting effects. In: Journalism and Mass Communication Quarterl, vol.74, n.4, winter, 1997, pp.703-717.

SEGRIN, C.; NABI, R. Does television viewing cultivate unrealistic expectations about marriage?. In: Journal of Communication, vol.52, june-2002, pp.247-263.

PERLOFF, RICHARD M. Third-person Effect research 1983-1992: a review and synthesis. In: International Journal of Public Opinion Resarch, vol.5, n.2, 1993, p.167-184.

SHEN, Fuyuan. Chronic Accessibility and Individual Cognitions: examining the effects of message frames in political advertisements. In: Journal of Communication, vol.54, n.1, março-2004, pp.123-137.

SHRUM, L. J. Processing strategy moderates the cultivation effect. In: Human Communication Resarch, vol.27, n.1, january-2001, pp.94-120.

WOLF, Mauro. Teorias da comunicação de massa. 2ed. São Paulo: Martins Fontes, 2005.

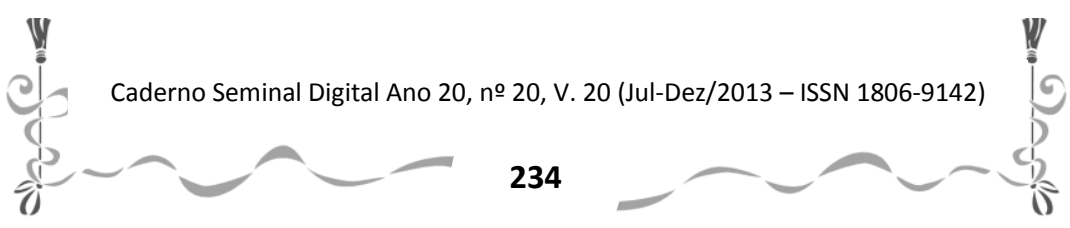

